\title{
Erratum to: Differential expression of stem cell markers in human follicular bulge and interfollicular epidermal compartments
}

\author{
Shu Jiang • Longmei Zhao • Bhamini Purandare • \\ Basil M. Hantash
}

Published online: 17 September 2010

(c) Springer-Verlag 2010

\section{Erratum to: Histochem Cell Biol (2010) 133:455-465 \\ DOI 10.1007/s00418-010-0684-z}

In the original publication of this article, acknowledgement of a funding source was accidentally missed.

The acknowledgement should have read:

We thank Dr. Jian Zhang for help in designing several of the primers used in this study. This work was supported by a generous gift from the Minnesota Jewish Foundation (2006) and an ASDS Cutting Edge Grant (2006 and 2007), both of which were awarded to Basil M. Hantash. Bhamini Purandare, MS, was supported by a training grant (TB101195) from the California Institute of Regenerative Medicine (2009).

The online version of the original article can be found under doi:10.1007/s00418-010-0684-z.

S. Jiang · L. Zhao - B. M. Hantash ( $₫)$

Division of Plastic Surgery, Department of Surgery,

Stanford University School of Medicine,

257 Campus Drive, Stanford, CA 94305, USA

e-mail: bhantash@stanford.edu

B. Purandare

San Jose State University, San Jose, CA, USA 